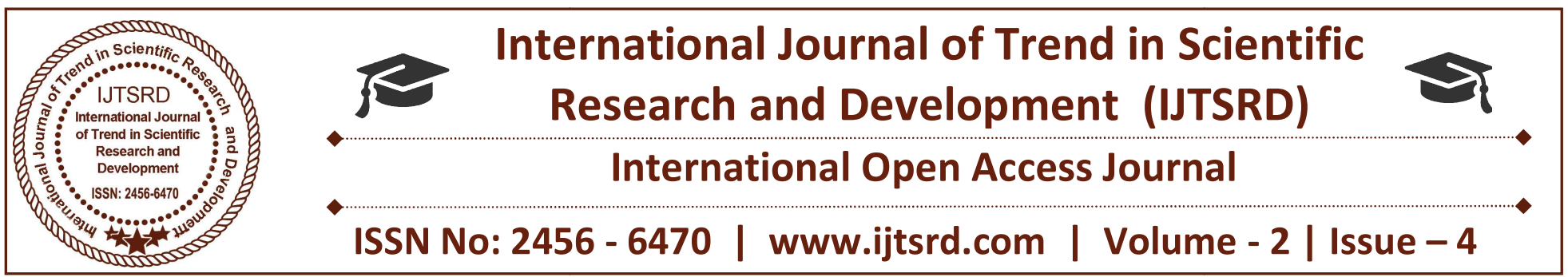

\title{
Automatic Gemstone Setting Machine in Jewels
}

\author{
Devendran. $\mathrm{P}^{1}$, Ajithkumar $\mathrm{P}^{2}$, Ranjith $\mathrm{R}^{2}$, Arun Prasath $\mathrm{S}^{2}$, Santhosh Balaji $\mathrm{V}^{2}$ \\ ${ }^{1}$ Assistant Professor, Department of Mechatronics Engineering, SNS College of Technology, Coimbatore, India \\ ${ }^{2}$ UG Scholar, Department of Mechatronics Engineering, SNS College of Technology, Coimbatore, India
}

\section{ABSTRACT}

Because of increment utilizing of mechanical robot arms, an advancement to that theme started attempting to emulate human developments in a detail mode. For instance a gathering of understudies in Korea made an outline of development that mechanical arm assess moving hand, weight lifting, chine's calligraphy composing and shading arrangement. Another gathering of designers at USA create eight level of flexibility robotic arm. This robot can get a handle on numerous articles with a great deal of shapes from a pen to a ball and reproducing likewise the hand of person. In space, the space, carry remote controller framework, known as SSRMS or Canadair, and its successor is case of multi level of opportunity robot arm that have been utilized to play out an assortment of assignments, for example, review of the bus utilizing a uniquely conveyed blast with cameras and sensors joined toward the end effectors. In this venture we utilize a mechanical arm to pick and place the gemstone in the gems. The possibility of the venture is to build up a moderate machine to make the gemstone setting process in gems simple. The target can be accomplished by actualizing the Independent Robot setup (3-arrange Pivot) to PICK and PLACE the gemstone into the decorations in a predefined position. A sensor is utilized to recognize the area of the gap where the stone is to be put in the trimming. And after that stone is come to that pre characterized position utilizing an automated arm which is accomplished by a small scale controller. The fundamental intention of the framework is to keep away from the breakage of stone and also the adornments. The framework will lessen the human effort and give a high accurate finishing to the adornments at less cost \& time.

Keywords: Robotic arm, Pick \& Place;

\section{INTRODUCTION:}

The term of mechanical technology is for all intents and purposes characterized as the examination, outline and utilization of robot framework for assembling. Robots are by and large used to play out the perilous, dangerous, exceptionally dull, and obnoxious undertakings. They have distinctive capacities, for example, material taking care of, get together, welding, and machine device stack and empty capacity, painting, and showering, and so forth. There are for the most part two various types of robots, for example, benefit robot and a mechanical apply autonomy. Administration robot is a robot that work semi or completely independently to perform administrations valuable to the prosperity of people and gear, barring fabricating task. Mechanical robots, on other hand, are authoritatively characterized by ISO as a consequently controlled and multipurpose programmable in at least three hub. Modern robots are intended to move material, devices, or particular gadget through factor customized movement to play out an assortment of assignments. A mechanical robots framework incorporates modern robots as well as any gadget or potentially sensor required for the robot to play out its assignments and in addition sequencing or checking correspondence interfaces. In 2007 the world market developed by $3 \%$ with around 114,000 new introduced mechanical robots. Toward the finish of 2007 there were around one million 
mechanical robots being used, contrasted and an expected 50,000 administration robots for modern utilize. The greater part of the robots are set up for a task by educate and rehash system. In this mode, a prepared administrator (software engineer) normally utilizes a compact control gadget (an instruct pendent) to educate a robot it's physically. Robot speeds amid these programming sessions are moderate.

The mechanical structure of a robot resembles the skeleton in human body. The robot life systems is in this manner, the investigation of structure of robot is physical development of the controller structure. The mechanical structure of controller the comprises of inflexible bodies(links) associated by means or joints, is portioned into an arm that guarantees portability and achieves capacity ,a wrist that gives introduction, and an end effector that plays out the required undertaking.

Controller is built of a progression of joints and connection, a joint gives relative movement between input connections and yield joins.

\section{MOTIVATION OF THE PROJECT:}

In this modern era, the human attraction towards jewellery has increased enormously from the past decade. The ornaments like Gold, Platinum, Diamond etc. should be handled very cautiously because even the small error could impact a huge loss to the organization in manufacturing. The current manufacturing process for making a precious stone ornament is carried out manually with highly skilled workers. Still, in many cases, human error exists, which causes loss to the organization. The main loss is caused by the stone setting process. In this process, high amount of skill and accuracy is needed for setting the stones in the ornament. This project aims to overcome the human errors and losses to the organization. In order to reduce those losses, an alternative modern approach is needed to be implemented. The human errors can be eliminated by automating the process of stone setting in the ornaments. The automation process is done with a help of a 3-axis pick and place robot which picks and places the stone in the desired coordinate.

\section{METHODOLOGY:}

This automatic gem setting machines are done with the control of pic controller. This controller controls the robotic arm and also helps in placing the stone automatically to the respective position which are already determined and programmed. The system consists of relays, de motor, servomotor, lcd unit, power supply and controller by which the whole process is controlled.

$5 \mathrm{v}$ battery is the source for the automatic stone setting machine. The input power through the battery is provided and pic controller is used to controlling the placement of the stones to the respective places as per determined. Then 2 servo motor are used in the joint of the robotic arm for the accurate movement of the arm and dc motor are used for the conversion of electric energy into mechanical energy and also helps in handling of stone. Then the stone setting is controlled using 4 buttons and position for those buttons are pre-defined and it is programmed. A, B ,C and $\mathrm{D}$ buttons are provided at different angles around the robotic arm, when each button is pressed the robotic arm move to that respective position.

\section{COMPONENTS:}

\section{BATTERY:}

An electric battery is a device consisting of one or more electrochemical cells with external connections provided to power electrical devices such as flashlights, smart phones, and electric cars .When a battery is supplying electric power, its positive terminal is the cathode and its negative terminal is the anode. The terminal marked negative is the source of electrons that when connected to an external circuit will flow and deliver energy to an external device. When a battery is connected to an external circuit, electrolytes are able to move as ions within, allowing the chemical reactions to be completed at the separate terminals and so deliver energy to the external circuit. It is the movement of those ions within the battery which allows current to flow out of the battery to perform work. It is made up $\mathrm{f}$ lead-peroxide.

\section{BATTERY CALCULATION}

$\mathrm{BAH} / \mathrm{CI}=8 \mathrm{Ah} / 420 \mathrm{~mA}=19 \mathrm{hrs}$ (4)

To find the Current Watt $=18 \mathrm{~W}$ Volt $=12 \mathrm{~V}$ Power, $\mathrm{P}=\mathrm{V} \times \mathrm{I}$ Current, $\mathrm{I}=1.5 \mathrm{~A}$

\section{BATTERY USAGE WITH $1.5 \mathrm{~A}=\mathrm{BAH} / \mathrm{I}=5.3 \mathrm{hrs}$.}

\section{POWER SUPPLY:}

A power supply circuit is used to convert the battery high voltage DC to 5v DC. Voltage regulator (ic7805) is used to convert high volt DC to $5 \mathrm{~V} \mathrm{DC}$.

\section{MICROCONTROLLER:}

Microcontroller is a general purpose device, which integrates a number of the components of a 
microprocessor system on to single chip. It has inbuilt $\mathrm{CPU}$, memory and peripherals to make it as a mini computer. Micro controller is a standalone unit, which can perform functions on its own without any requirement for additional hardware like i/o ports and external memory. The microcontroller used is PIC16F\&18F.

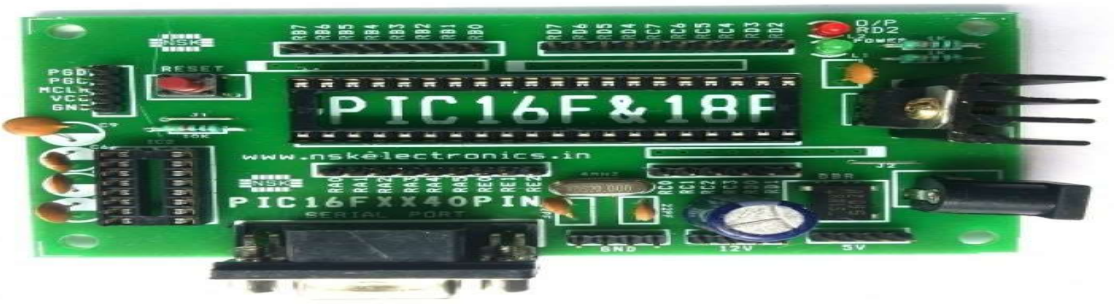

\section{LCD:}

LCD (Liquid Crystal Display) screen is an electronic display module and find a wide range of applications. A $16 \times 2$ LCD display is very basic module and is very commonly used in various devices and circuits. It has 14 pins. It uses 8lines for parallel data plus 3 control signals, 2 connections to power, one more for contrast adjustment and two connections for LED back light.

\section{MOTOR:}

A DC motor is electrical machine that converts direct current electrical power into mechanical power. Its movement is produced by the physical behaviour of electromagnetism. DC motors have inductors inside, which produce the magnetic field used to generate movement.

\section{RELAY:}

A relay is an electromagnetic switch operated by a relatively small electric current that can turn on or off a much larger electric current. The heart of a relay is an electromagnet (a coil of wire that becomes a temporary magnet when electricity flows through it). General purpose relays operate with $\mathrm{AC}$ or $\mathrm{DC}$ current, at common voltages such as $12 \mathrm{~V}, 24 \mathrm{~V}, 48 \mathrm{~V}$, $120 \mathrm{~V}$ and $230 \mathrm{~V}$, and they can control currents ranging from $2 \mathrm{~A}-30 \mathrm{~A}$. Here we are using $12 \mathrm{v}$ relay.

\section{SERVO MOTOR:}

A servomotor is a rotary actuator or linear actuator that allows for precise control of angular or linear position, velocity and acceleration. It consists of a suitable motor coupled to a sensor for position feedback. It also requires a relatively sophisticated controller, often a dedicated module designed specifically for use with servomotors.
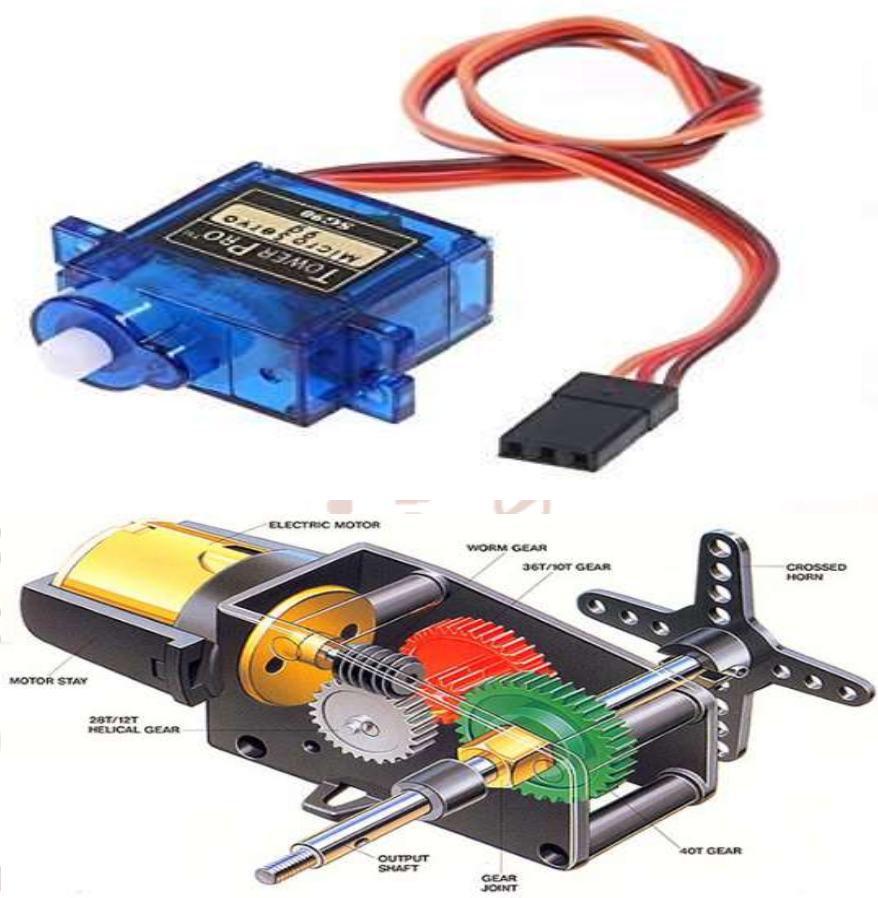

Servo motor specifications

SPECS OF A LARGE SERVO MOTOR

Size:

$38 \times 11.5 \times 24 \mathrm{~mm}$ (Include tabs) $28 \times 12.7 \times 27 \mathrm{~mm}$ (Not include tabs)

Weight:

$17 \mathrm{~g}$ (Not include a cable and a connector) $18 \mathrm{~g}$ (Include a cable and a connector)

Speed:

$0.14 \mathrm{sec} / 60$ degrees $(4.8 \mathrm{~V}) 0.12 \mathrm{sec} / 60$ degrees $(6.0 \mathrm{~V})$

Torque:

$2.5 \mathrm{kgf}-\mathrm{cm}(4.8 \mathrm{~V}) 3.0 \mathrm{kgf}-\mathrm{cm}(6.0 \mathrm{~V})$

Voltage: 
$4.8 \mathrm{~V}-6.0 \mathrm{~V}$

Connector type:

JR type '(Yellow: Signal, Red: VCC, Brown: GND)'

\section{SPECS OF A SMALL SERVO MOTOR}

Size:

$38 \times 11.5 \times 24 \mathrm{~mm}$ (Include tabs) $28 \times 12.7 \times 27 \mathrm{~mm}$ (Not include tabs)

Weight:

$17 \mathrm{~g}$ (Not include a cable and a connector) $18 \mathrm{~g}$ (Include a cable and a connector)

Speed:

$0.14 \mathrm{sec} / 60$ degrees $(4.8 \mathrm{~V}) 0.12 \mathrm{sec} / 60$ degrees $(6.0 \mathrm{~V})$

Torque:

$2.5 \mathrm{kgf}-\mathrm{cm}(4.8 \mathrm{~V}) 3.0 \mathrm{kgf}-\mathrm{cm}(6.0 \mathrm{~V})$
Voltage:

$4.8 \mathrm{~V}-6.0 \mathrm{~V}$

Connector type:

JR type (Yellow: Signal, Red: VCC, Brown: GND)

\section{FORMULA USED}

Torque $(\mathrm{oz}-\mathrm{in})=8.5 \mathrm{E}-6 *(\mathrm{C} 2 \mathrm{~V} 2 \mathrm{~L} \sin (\mathrm{S} 1) \tan (\mathrm{S} 1) /$ $\tan (\mathrm{S} 2))$

Where:

$\mathrm{C}=$ Control surface chord in $\mathrm{cm}$

$\mathrm{L}=$ Control surface length in $\mathrm{cm}$

$\mathrm{V}=$ Speed in MPH

$\mathrm{S} 1$ = Max control surface deflection in degrees

$\mathrm{S} 2$ = Max servo deflection in degrees
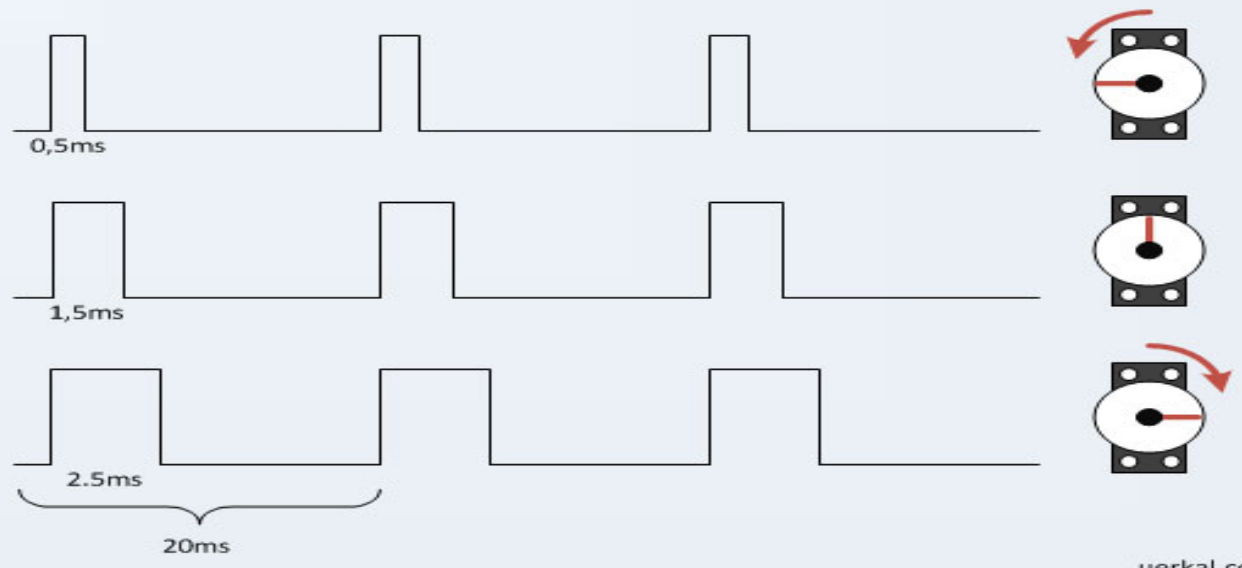

uerkal.com

\section{OUTCOME EXPECTED:}

- By using automatic gem setting the wastage of stone is minimized

- The work time for setting the stone is very less when compared with manual setting.

- It requires less man power

- It mainly reduces all sort of wastage

\section{ACKNOWLEDGEMENT:}

We take immense pleasure in expressing our humble note of gratitude to our project guide Mr.P.Devendran assistant professor of mechatronics engineering for his remarkable guidance in doing our project.

\section{REFERENCES}

1. Chapen, J.R., Moxon, K.A., Markowitz, R.S.\& Nicolelis, M.A.L. Nat, Neurosci. 2, 664670(1999).

2. Porter R. \& Lemon, R. Corticospinal Function and Voluntary Movement (Clarendon, Oxford,1993).

3. Humphrey,D. R., Schmidit, E.M.\& Thompson,W.D. Science 179,758-762(1970).

4. Humphrey,D. R., \& Hochberg, L., Proc. Rehab. Eng. Soc. N. Am 15, 650-658(1995).

5. Humphrey, D. R., Reed, D., Hochberg, L., \& Burrow, M. Final report, NIH/NINDS Contract NO1-NS-1-2308(1997). 
6. LUKASHIN, A. V., Amirikian, B. R. \& 9. Fetz, E. E. \& Finocchio, D.V. Exp. Brain Res. Georgopoulous, A. P., Neuroreport 7, 2597-2601 (1996).

7. Schwartz, A. B. J. SCIENCE 265, 540-542 (1994).

8. Fetz, E. E. \& Baker, M.A. J. Neurophysiol. 36, 179-204 (1973). 23,217 -240 (1975).

10. Iriki, A., Tanaka, M. \& Iwamura, Y. Neuroreport 9,1707-1711(1998).

11. Kennedy, P. R. \& Vakay, R. A. E. Neuroreport 7,2325-2330 (1975).

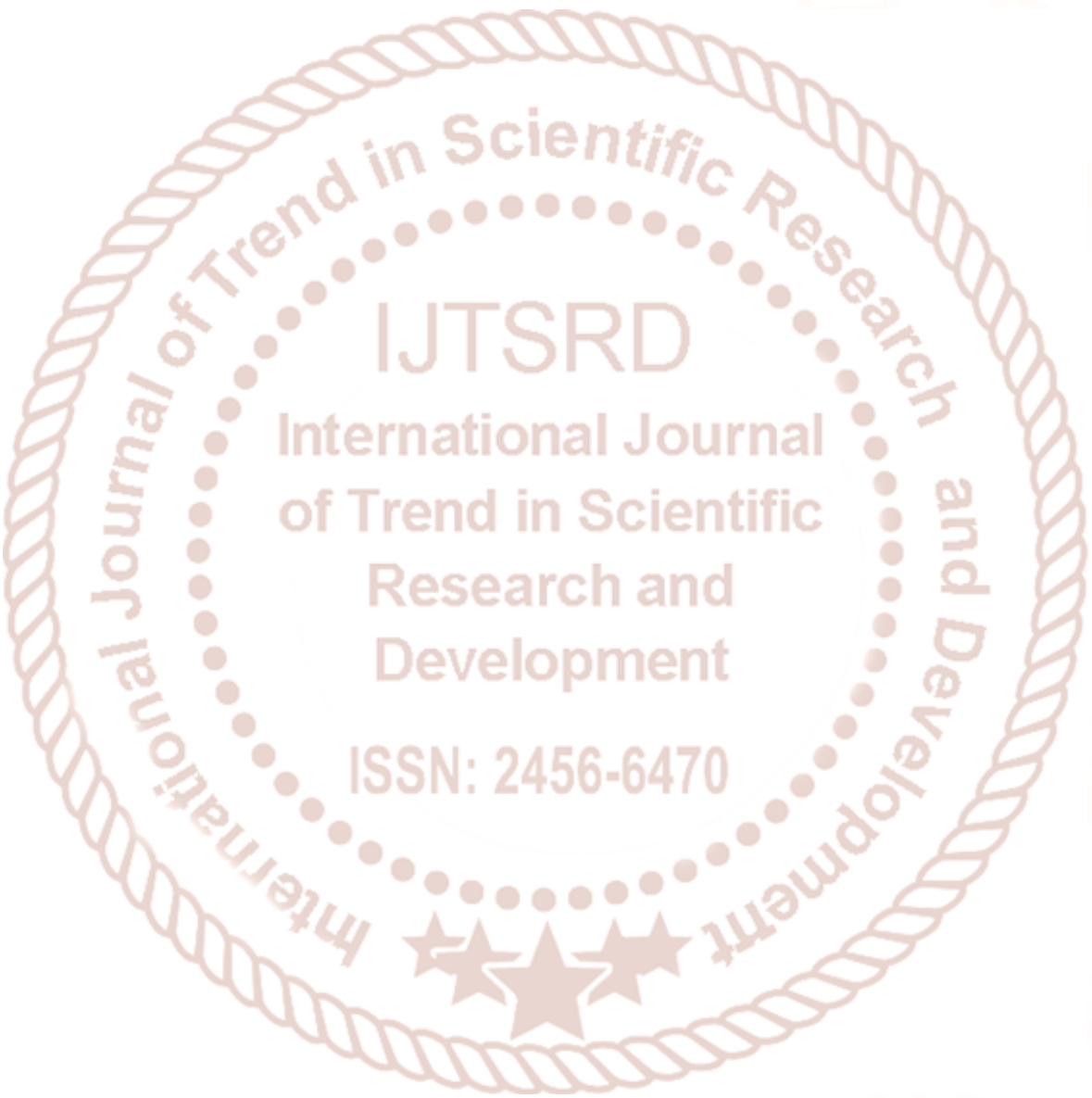

